\title{
Molecular pathways of pannexin1-mediated neurotoxicity
}

\author{
Valery I. Shestopalov ${ }^{1,2,3 *}$ and Vladlen Z. Slepak ${ }^{4,5}$ \\ ${ }^{1}$ Department of Ophthalmology, Bascom Palmer Eye Institute, University of Miami Miller School of Medicine, Miami, FL, USA \\ ${ }^{2}$ Department of Cell Biology and Anatomy, University of Miami Miller School of Medicine, Miami, FL, USA \\ ${ }^{3}$ Vavilov Institute of General Genetics, Moscow, Russian Federation, University of Miami Miller School of Medicine, Miami, FL, USA \\ ${ }^{4}$ Department of Molecular Pharmacology, University of Miami Miller School of Medicine, Miami, FL, USA \\ ${ }^{5}$ Neuroscience Program, University of Miami Miller School of Medicine, Miami, FL, USA
}

\section{Edited by:}

Georg Zoidl, York University, Canada

Reviewed by:

Francisco F. De-Miguel, Universidad

Nacional Autónoma de México,

Mexico

Lisa Ebihara, Rosalind Franklin

University of Medicine and Science,

USA

\section{*Correspondence:}

Valery I. Shestopalov, Department of Ophthalmology, Bascom Palmer Eye Institute, University of Miami Miller School of Medicine, 1638 NW 10th Avenue, Miami, FL 33136, USA e-mail:vshestopalov@

med.miami.edu
Pannexin1 (Panx1) forms non-selective membrane channels, structurally similar to gap junction hemichannels, and are permeable to ions, nucleotides, and other small molecules below $900 \mathrm{Da}$. Panx1 activity has been implicated in paracrine signaling and inflammasome regulation. Recent studies in different animal models showed that overactivation of Panx 1 correlates with a selective demise of several types of neurons, including retinal ganglion cells, brain pyramidal, and enteric neurons. The list of Panx 1 activators includes extracellular ATP, glutamate, high $\mathrm{K}^{+}, \mathrm{Zn}^{2+}$, fibroblast growth factors (FGFs), pro-inflammatory cytokines, and elevation of intracellular $\mathrm{Ca}^{2+}$. Most of these molecules are released following mechanical, ischemic, or inflammatory injury of the CNS, and rapidly activate the Panx 1 channel. Prolonged opening of Pan $\times 1$ channel induced by these "danger signals" triggers a cascade of neurotoxic events capable of killing cells. The most vulnerable cell type are neurons that express high levels of Panx1. Experimental evidence suggests that Pan $x 1$ channels mediate at least two distinct neurotoxic processes: increased permeability of the plasma membrane and activation of the inflammasome in neurons and glia. Importantly, both pharmacological and genetic inactivation of Panx1 suppresses both these processes, providing a marked protection in several disease and injury models. These findings indicate that external danger signals generated after diverse types of injuries converge to activate Panx1. In this review we discuss molecular mechanisms associated with Panx1 toxicity and the crosstalk between different pathways.

Keywords: hemichannel, neurotoxicity, danger signals, pannexin, neuronal death, inflammasome, calcium, signaling
Connexin and pannexin families of channel proteins connect cells to the environment by forming unpaired halfchannels (hemichannels) in the plasma membrane (Bennett and Goodenough, 1978; Jones et al., 1997; Johnson and Owens, 1999). In contrast to gap junctions that mediate direct electrical and metabolic coupling between cells (Goodenough et al., 1980; Draguhn et al., 1998; Bennett and Zukin, 2004), hemichannels support cell-environment communication and paracrine signaling (Jones et al., 1997; Kumar et al., 2004). For example, Pannexin1 (Panx1), which forms predominantly hemichannels, was shown to be involved in paracrine signaling when activated by ATP, UTP, and adenosine. In neurons, Panxl hemichannels are implicated in electrical communication (Iglesias and Spray, 2012), metabolic autocrine regulation (Kawamura et al., 2010), short-term memory formation (Prochnow et al., 2012), regulation of cell volume during high activity (Wurm et al., 2008, 2010; Li et al., 2012), proliferation and migration of neural stem cells (Wicki-Stordeur et al., 2012), apoptotic "find me" signaling (Chekeni et al., 2010; Sandilos et al., 2012) and possibly other homeostatic functions.

It is known that, under conditions of stress and injury, neural cells rapidly decrease intercellular communication via gap junctions and, instead, switch to hemichannels formed by either connexins or pannexins that communicate with the environment (Melov et al., 2007; Kim et al., 2008; Orellana et al., 2009). These changes are likely modulated by growth factors, such as FGFs (Reuss et al., 2000; Orellana et al., 2009; Garre et al., 2010). Active involvement of hemichannels, particularly Panx1, has been documented in various CNS and PNS pathologies, including hippocampal neuron ischemia (Thompson et al., 2006), retinal ischemia-reperfusion, in human spinal cord injury and thromboembolytic stroke, white matter ischemic injuries, spreading depression, inflammatory enteric colitis, and pain formation (de Rivero Vaccari et al., 2008; Zhang et al., 2008; Abulafia et al., 2009; Domercq et al., 2010; Orellana et al., 2010; Bargiotas et al., 2011; Dvoriantchikova et al., 2012b; Karatas et al., 2013). Experimental data from both pharmacological blockade of the Panxl channel and genetic ablation of its gene supports a model where Panx 1 activation is pivotal for facilitating selective neuronal demise in these pathologies.

Interestingly, Panx1 expression level in retinal ganglion and other neurons is at least 10 times lower than Cx36. However, as indicated above genetic ablation or pharmacologic blockade of Panx1, but not the Cx36 is profoundly neuroprotective in the injured retina. In contrast, the deficiency in functional Cx36 has been liked to secondary degeneration following retinal injury 
(Striedinger et al., 2005). Taken together, the relatively low expression levels and profound effect of the knockout, indicate that Panx1 activation is particularly neurotoxic (Bargiotas et al., 2011; Dvoriantchikova et al., 2012b).

\section{TOXICITY-ASSOCIATED PROPERTIES OF PANNEXIN-1 CHANNELS}

Experimental evidence indicates that unique physiological properties of the Panx1 channel, including permeability to $\mathrm{Ca}^{2+}$, ATP, and other small molecules contribute to the pathophysiology of neuronal injury (Bao et al., 2004; Barbe et al., 2006; Locovei et al., 2006a,b; Pelegrin and Surprenant, 2006; Thompson et al., 2006). Unlike connexins, which are closed at physiological concentrations of extracellular $\mathrm{Ca}^{2+}$ (Barbe et al., 2006), pannexins remain open and can pass extracellular $\mathrm{Ca}^{2+}$ across the plasma membrane (Vanden Abeele et al., 2006). Furthermore, Panx1 hemichannels open in response to elevated intracellular $\mathrm{Ca}^{2+}$ (Locovei et al., 2006b), contributing to a rapid post-injury entry of extracellular $\mathrm{Ca}^{2+}$ into the cell ("calcium overload") following various injuries. Indeed, several studies showed that Panx1 activation facilitates $\mathrm{Ca}^{2+}$ passage across the plasma membrane (Vanden Abeele et al., 2006; Thompson et al., 2008; Dvoriantchikova et al., 2012b; Weilinger et al., 2013) (Figure 1).

Another immediate consequence of a prolonged activation of Panxl channel is the efflux of ATP into the extracellular space (Bao et al., 2004; Reigada et al., 2008). Extracellular ATP activates purinergic P2 receptors at the cellular surface, induces IP3-mediated $\mathrm{Ca}^{2+}$ release from the endoplasmic reticulum storage and downstream signaling cascades associated with inflammation, and results in neurotoxicity. Compared with connexin, pannexin hemichannels have superior permeability to ATP, thus representing a major release pathway from stressed or injured neurons and, possibly, glia (Iglesias et al., 2009; Iglesias and Spray, 2012; Prochnow et al., 2012; Xia et al., 2012; Dahl et al., 2013). That said, glial cells may also release ATP via the Cx43 hemichannels, as shown by several investigators (Saez et al., 2010; Orellana et al., 2011). This mechanism, however, was questioned by others (Iglesias et al., 2009; Suadicani et al., 2012) because ATP release was disrupted in Panx1-null astrocytes but remained unaffected in Cx43-null astrocytes. Therefore, it is reasonable to suggest that Panx1, which is particularly abundant in several types of CNS neurons (Bruzzone et al., 2003; Dvoriantchikova et al., 2006; Zoidl et al., 2007), is directly responsible for the raise in extracellular ATP and intracellular $\mathrm{Ca}^{2+}$, the two major events leading to CNS injury.

In contrast to connexins, Panxl can be activated by a broad spectrum of extra- and intracellular stimuli. Many of these danger signals are released after injuries and in pathologies and include (in addition to ATP) extracellular $\mathrm{K}^{+}$and $\mathrm{Zn}^{2+}$, glutamate, and pro-inflammatory cytokines. Within apoptotic cells, Panxl is irreversibly activated by proteolysis with caspases 3 and 7 (Bao et al., 2004; Barbe et al., 2006; Brough et al., 2009; Bunse et al., 2009; Orellana et al., 2009; Chekeni et al., 2010). Panx1 is also mechanosensitive and opens by the stretch of the plasma membrane that occurs during changes in osmolarity or mechanical injuries. The result of a prolonged Panxl activation is massive influx of ions and small molecules into the cell and the efflux of ATP and UTP, as schematically shown in Figure 1.

\section{FUNCTIONAL INTERACTIONS WITH RECEPTORS AND CHANNELS}

Key interaction partners for Panx1 include surface receptors and channels, which can be grouped by the following molecular consequences: (i) interactions modulating intracellular $\mathrm{Ca}^{2+}$, which include NMDA, P2X, and TRPV4 receptors; (ii) interactions with $\mathrm{Ca}^{2+}$-mobilizing $\mathrm{G}$ protein-coupled receptors, such as $\mathrm{P} 2 \mathrm{Y}$ and PAR1 receptors that mobilize intracellular $\mathrm{Ca}^{2+}$ and activate $\mathrm{PKC}$; (iii) interactions leading to ATP/ADP/adenosine signaling that also include purinergic $\mathrm{P} 2 \mathrm{X}$ receptors (P2XRs) (Figure 1). Available data suggest that direct binding partners of Panx1 are P2XRs and actin filaments. Functional modulators include NMDA, A1/A2 adenosine receptors, $\mathrm{Kv} \beta 3$ potassium channels and fibroblast growth factor-1 (FGF-1) (Bunse et al., 2009; Garre et al., 2010).

Currently, the most established mechanism of cell injury in post-ischemic neurons is $\mathrm{Ca}^{2+}$ entry via ligand-gated channels, such as NMDA receptor (NMDAR) and P2XRs (Lazarewicz et al., 1990; Lobner and Lipton, 1993; Sucher et al., 1997; Franke et al., 2006; Hardingham, 2009; Matute and Cavaliere, 2011). However, recent studies indicated that these $\mathrm{Ca}^{2+}$ entry mechanisms are significantly facilitated by Panx1 channel activity (Zhang et al., 2005a; Thompson et al., 2008; Orellana et al., 2011; Gulbransen et al., 2012; Weilinger et al., 2013). Thus, according to Thompson and co-authors, Panxl opening is synergistic with activation of NMDAR and can be facilitated by NMDA or glutamate (Thompson et al., 2008; Weilinger et al., 2013). This group also recently showed that both NMDAR antagonists, attenuated currents carried by Panx1 and the SFK-Panx1 interfering peptide significantly reduced anoxic depolarization, and $\mathrm{Ca}^{2+}$ influx in OGD (Weilinger et al., 2012). According to their model, Panx1 activation occurs downstream of NMDAR and is mediated by Src family kinases. If this model is correct, $\mathrm{Ca}^{2+}$ overload after ischemic injury occurs via both NMDAR channel activity and the opening of Panx1. Thus, extracellular glutamate is one of several major pathological factors can facilitate Panxloveractivation and the ensuing neurotoxicity.

$\mathrm{Ca}^{2+}$ can also enter cells via the purinergic P2XRs activated by extracellular ATP, and via transient receptor potential vanilloid receptors (e.g., TRPV4) activated by mechanical stress (Mochizuki et al., 2009; Ryskamp et al., 2011). Panxl can facilitate both these mechanisms to the point that transient extracellular $\mathrm{Ca}^{2+}$ changes are converted into the pathogenic overload. Furthermore, ATP can be released via Panx1, further activating P2XRs in paracrine or autocrine fashion (Figure 1). Functional interaction between P2X7 receptor and Panx1 was first reported to occur in macrophages by Pelegrin and Surprenant (2006), who suggested on the basis of co-immunoprecipitation of ectopically expressed Panx1 and P2XR isoforms that these two proteins can interact directly. P2X7-dependent opening of the Panx1 channel in response to ATP has been demonstrated in diverse pathological settings, prompting researchers to name Panx1 "the pore-forming unit of P2X7R-death complex” (Locovei et al., 2007; Iglesias et al., 2008). In the CNS, a similar role was suggested for Panx1 complex with P2X4R (de Rivero Vaccari et al., 2012), which is expressed 


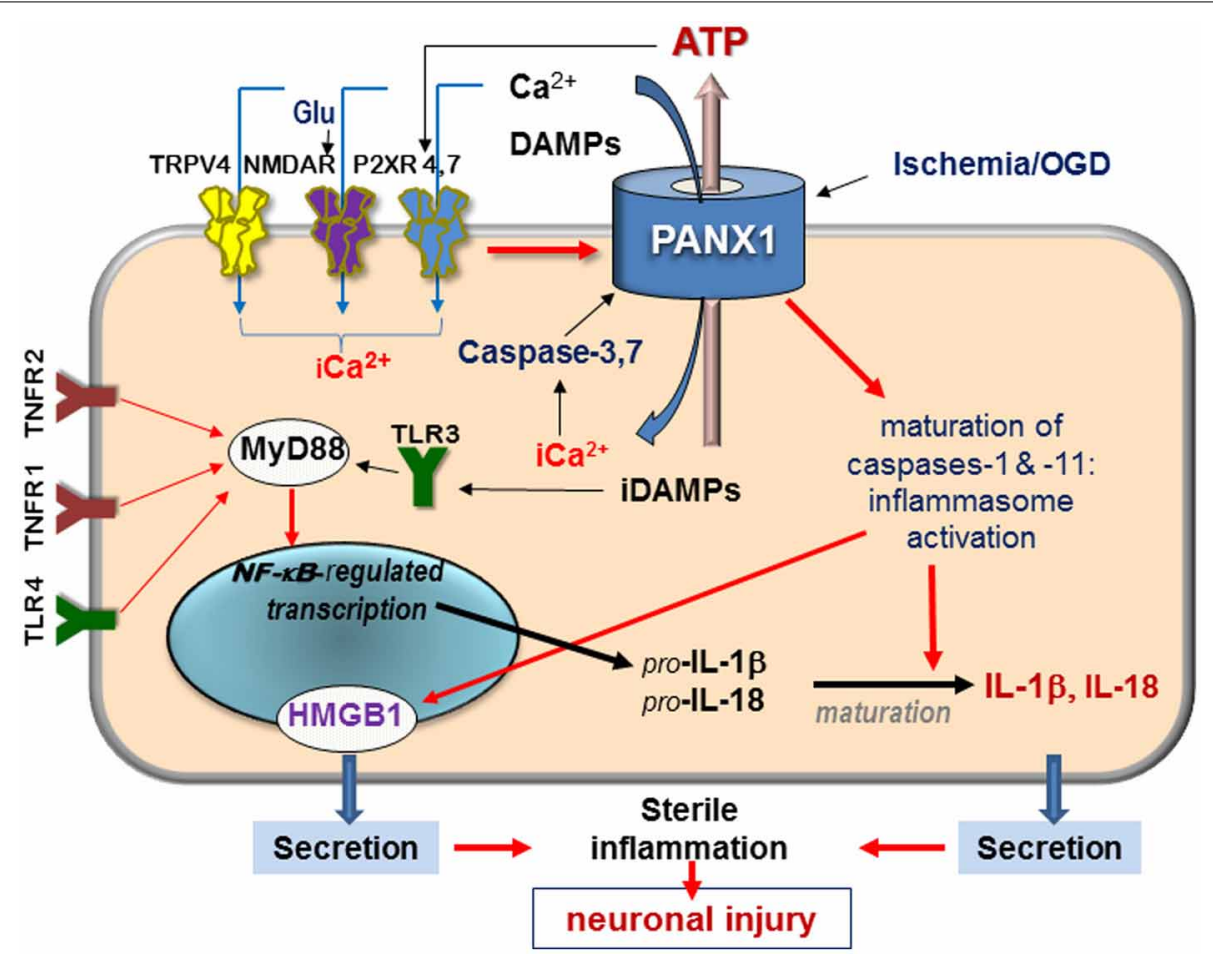

FIGURE 1 | Schematic diagram of signaling mediated by surface receptors and Panx1-in the injured retina in response to ischemia and extracellular danger signals. Abbreviations: Glu, glutamate; DAMPs, danger-associated molecular patterns; $\mathrm{iCa}^{2+}$, intercellular free calcium; TRPV, transient receptor potential vanilloid, NMDAR, N-methyl-D-aspartate receptor; P2XR, purinergic 2 receptor; TLR, Toll-like receptor, TNFR, tumor necrosis factor receptor; HMGB1, high-mobility group protein B1; red arrows denote activation pathways. more abundantly than P2X7R in neurons of the spinal cord and in retinal ganglion cells. Physical interaction between Panx1 and P2XRs 2,3,4, and 7 were shown by co-immunoprecipitation in rat pituitary cells (Li et al., 2011). Studies showed that Panx1mediated ATP release in certain cell types can also occur in response to activation of metabotropic $\mathrm{P} 2 \mathrm{Y} 1$ and $\mathrm{P} 2 \mathrm{Y} 2$ receptors (Locovei et al., 2006b; Zhang et al., 2012).

Interactions between TRPV4 channel and Panx1 hemichannel were reported recently in the airway and ocular lens epithelium (Seminario-Vidal et al., 2011; Shahidullah et al., 2012). These results indicate that TRPV4 and associated Rho activity can transduce cell membrane stretch to Panx1, which releases ATP (Iglesias et al., 2008). As was suggested recently (Krizaj et al., 2013), this novel model can provide feasible explanation for severe $\mathrm{Ca}^{2+}$ disregulation observed in retinal disorders linked to mechanical stretch of the retina, such as intraocular pressure-induced primary glaucoma. Importantly, TRPV4 activation was shown to predispose RGCs to death via $\mathrm{Ca}^{2+}$-dependent pro-apoptotic signaling pathways (Ryskamp et al., 2011). Additional binding partners and modulators of Panx1 activity are A1 and A2 adenosine receptors (Kawamura et al., 2010), Kv $\beta 3$ potassium channels (Bunse et al., 2009), FGF-1 (Garre et al., 2010), actin microfilaments (Bhalla-Gehi et al., 2010; Bao et al., 2012), and thrombinspecific protease-activated receptor 1 (PAR-1) (Godecke et al., 2012). The significance of these recently detected interactions remains to be determined.
Interestingly, in many cell types expressing P2XRs, receptorinduced opening of the Panxl channel is a relatively late event that is preceded by the rapid opening of the receptor channel and occurs after a prolonged agonist application. Prior to the discovery of pannexins, this delay was explained as a slow development of a large pore via progressive dilation of $\mathrm{P} 2 \mathrm{XRs}$ themselves upon continuous/repetitive application of agonist (Innocenti et al., 2004; Gourine et al., 2007). However, later studies showed that Panxl is required for generation of the characteristic large current $(\sim 500 \mathrm{pS})$ and permeability to molecules up to $900 \mathrm{Da}$ (Pelegrin and Surprenant, 2006, 2009; Locovei et al., 2007; Iglesias et al., 2008). In the complex with Panx1 channel, stimulation of P2XRs leads to significantly higher currents compared to the activation of either P2XRs, NMDAR, or TRPV4 alone. These experiments allowed researchers to separate receptor activation and Panxl opening events (Iglesias et al., 2008). Physiologically, the delayed Panx1 opening may provide for a tighter control of this large cell-permeating pore, so that only abnormally high level of activation would amplify $\mathrm{Ca}^{2+}$ uptake and ensuing neurotoxicity (Locovei et al., 2007). Indeed, several lines of experimental data indicate that ischemia-mediated Panx1 opening also occurs $10-20 \mathrm{~min}$ after the onset of ischemic conditions (Thompson et al., 2006; Zhang et al., 2008; Dvoriantchikova et al., 2012b; Weilinger et al., 2012). This delay could be attributed to lagging development of conditions favoring Panxl opening, 
such as anoxic depolarization and/or accumulation of agonists (danger factors).

\section{NEUROTOXIC SIGNALING MECHANISMS DOWNSTREAM OF Panx1}

What are the specific mechanisms of cell death downstream of P2XR(4,7)-Panx1 complex? The most thoroughly studied mechanism involves intercellular ionic dysbalance, mostly $\mathrm{Ca}^{2+}$ overload and the subsequent activation of $\mathrm{Ca}^{2+}$-dependent proteases including calpain and pro-apoptotic caspases (Dvoriantchikova et al., 2012b; Paramo et al., 2013; Weilinger et al., 2013) (Figure 1). The P2XR(4,7)-Panx1 complex has also been reported to activate several enzymatic pathways known to damage neuronal cells. The first one acts through the activation of ROSproducing enzyme NADPH oxidase (Seil et al., 2008; Barakat et al., 2012; Choi et al., 2012; Dvoriantchikova et al., 2012a). The second mechanism links P2XR(4,7)-Panx1 overactivation with a relatively new neurotoxic pathway, activation of the inflammasome (de Rivero Vaccari et al., 2012). Inflammasome is an intracellular macromolecular complex responsible for proteolytic processing and release of inflammatory interleukins IL-1 $\beta$ and IL-18 (Pelegrin and Surprenant, 2006; Kanneganti et al., 2007). Inflammasome was first characterized in macrophages and more recently in glia and neurons (Silverman et al., 2009). Activation of caspase-1, the principal component of the complex, was shown to be dependent upon Panx1 in both neuronal and glial cell types (Kanneganti et al., 2007; de Rivero Vaccari et al., 2009; Silverman et al., 2009) but is redundant in macrophages (Pelegrin et al., 2008; Qu et al., 2011). The role of inflammasome activation in human pathologies those affecting the CNS have been extensively reviewed elsewhere (Bernier, 2012; Dahl and Keane, 2012; Strowig et al., 2012; Fleshner, 2013), here we will cover this topic very briefly. Production of interleukins IL-1 $\beta$ and IL-18 depends on: (1) transcriptional activation of the interleukin gene and accumulation of the IL precursors; (2) proteolytic activation of caspase-1 within the inflammasome that is required to processes them into mature forms.

The pathway for transcriptional activation of the IL- $1 \beta$ and IL-18 genes requires activity of surface receptors, including tumor necrosis factor (TNFR) and Toll-like (TLR) receptors, and recruitment of the adapter protein $\mathrm{MyD} 88$, which is followed by activation of transcription factor NF- $\mathrm{KB}$ (Figure 1) (de Rivero Vaccari et al., 2008; Silverman et al., 2009). Parallel maturation of cytokines appears to be a crucial step in the neurotoxic pro-inflammatory program. This step requires Panx1 (Pelegrin and Surprenant, 2007; Dvoriantchikova et al., 2012b), and is independent on TLR activation (Kanneganti et al., 2007). The inflammasome is rapidly activated in the CNS in sterile (nonmicrobial) conditions in response to extracellular ATP and other DAMPs (Maher, 2009; Lamkanfi, 2011; Ayna et al., 2012; Riteau et al., 2012). It was also recently shown to be involved in the release of the pro-inflammatory nuclear protein high-mobility group B1 (HMGB1, or "alarmin") (Karatas et al., 2013; Li et al., 2013).

In the model of retinal ischemia-reperfusion, Panx1-mediated neurotoxicity correlated with robust activation of endogenous, neuronal inflammasome and the release of IL- $1 \beta$ in the ganglion cell layer, the site of major damage (Dvoriantchikova et al., 2012b). According to Pelegrin and co-authors, blocking the Panxl channels with siRNA, mimetic peptide or carbenoxolone in macrophages prevented large pore formation, caspase1 activation, and processing/release of IL- $1 \beta$ (Pelegrin and Surprenant, 2006; Pelegrin, 2008). The processing and release of IL-1 $\beta$ in the post-ischemic retina are significantly attenuated by Panx1 knockout (Bargiotas et al., 2011; Dvoriantchikova et al., 2012b). Similarly, experimental blocking of the inflammasome in the CNS through pharmacological inactivation or genetic ablation of either P2X7 receptor, Panx1, or any major component of the inflammasome complex, including caspase1, NALP, or ASC proteins, had exactly same effect and similar degree of neuroprotection (Zhang et al., 2005a; Arai et al., 2006; de Rivero Vaccari et al., 2009; Domercq et al., 2010). Striking similarity in the degree of neuroprotection upon inactivation of either Panx1 or inflammasome was observed in mouse models of enteric colitis (Gulbransen et al., 2012). Intriguingly, recent studies linked inflammasome activation with the onset of pyroptosis, an inflammatory form of programmed cell death (Franchi et al., 2012; Strowig et al., 2012). Another new non-apoptotic mechanisms of cell death that have been recently linked with ischemic retinal and brain injury, is necroptosis (Rosenbaum et al., 2010; Meloni et al., 2011). However, despite the profile of Panx1-mediated neurotoxicity matches that observed in necroptosis, no correlation between Panx1 activity and necroptosis marker RIP3 has been reported so far.

In addition to interleukin secretion, another pathway, the inflammasome-dependent release of nuclear protein alarmin/HMGB1 can facilitate neurotoxicity indirectly via gliamediated toxicity. This novel pathway has been recently demonstrated in both inflammatory and neuronal cells (Willingham et al., 2009; Lamkanfi et al., 2010). Initially thought to be released from necrotic or injured cells, massive HMGB1 release has been shown in live brain neurons affected by spreading depression (Karatas et al., 2013), but the mechanism of such release remains poorly characterized. The release of alarmin from live cells is triggered by a spectrum of distinct cytokines and/or danger signals produced during CNS stress or injury, and is recently shown to be controlled by Panx1 (Yang et al., 2010; Karatas et al., 2013). Furthermore, Karatas and coauthors showed that alarmin binds to glial RAGE receptors leading to activation of astroglial NF- $\mathrm{KB}$ pathway, which is one of the most potent source of glial neurotoxicity in CNS disorders (Bales et al., 1998; Brambilla et al., 2009, 2012; Dvoriantchikova et al., 2009; Barakat et al., 2012).

The Panx1 channel can provide the gateway for DAMPs/PAMPs to enter the cell and activate intracellular TLRs, such as TLR3, which has been implicated in several neurodegenerations, including glaucoma (Nowak and Davies, 2004; Zhang et al., 2005b; Shiose et al., 2011). These intracellular TLRs receptors signal to NF- $\mathrm{BB}$ and are expressed by both glial and microglial cells. These experiments demonstrated that ATP-induced Panx 1 channel opening provides an entry pathway for bacterial danger signals into the cytosol, where they facilitated the cryopyrin-dependent activation of caspase-1 (Kanneganti 
et al., 2007). When stimulated by ATP activation of P2X7R, Panxl was essential for proteolytic cleavage of caspase- 1 and the subsequent maturation and release of its substrate, IL-1 $\beta[24,46$, 47]. At the same time, the opening of Panxl hemichannels was shown to be independent of TLR activation [42], indicating that Panxl acts in parallel, not downstream of TLRs.

\section{THE ROLE OF Panx1 IN NEUROTOXIC GLIA-NEURON INTERACTIONS}

How does activation of the ubiquitously expressed Panxl result in selective injury and death of distinct neuronal types? Such selective vulnerability is consistent with high levels of Panxl expression in certain neuronal sub-populations, for example RGCs in the retina and hippocampal pyramidal neurons (Dvoriantchikova et al., 2006; Krizaj et al., 2013). An interesting model that proposed a role of activated glia in triggering death of such subpopulations was suggested by Orellana and co-authors. Using an in vitro cell culture approach, they showed that neuronal demise is triggered by synergistic action of high extracellular glutamate and ATP on neuronal Panx1 channel (Orellana et al., 2011). The mechanism of massive efflux of astroglial glutamate and ATP in their model was initiated through the release of TNF $\alpha$ and IL-1 $\beta$ cytokines from activated microglial cells. Additional studies are required to test whether this mechanism of action occurs in vivo.

Our model summarizing mechanisms underlying Panx1mediated pathophysiology is depicted in Figure 1. As mentioned above, Panx 1 is activated by diverse signaling pathways. In pathological conditions, Panxl activation parallels transcriptional activation of the TLR-MyD88-NF- $\kappa$ B pathway to synergistically facilitate production and secretion of pro-inflammatory interleukins IL-1 $\beta$ and IL-18. This model implies that transcriptional induction of MyD88-NF- $\kappa \mathrm{B}$ by the upstream signaling requires synchronization with activation of Panxl to achieve a successful cytokine release. Thus, activation of NF-kB-regulated gene transcription downstream of Toll-like and TNF receptors occurs in parallel with the activation of $\mathrm{P} 2 \mathrm{X}$ receptors and Panx1, thereby coordinating gene transcription with proteolytic processing of interleukins.

\section{PANX1 AS A PHARMACOLOGICAL TARGET}

Blockers of Panxl channel such as probenecid, mefloquine, and carbenoxolone (Iglesias et al., 2008; Silverman et al., 2008) have been used for several decades to treat gout, gastric ulcer and infection diseases such as malaria (Doll et al., 1965; Trenholme et al., 1975; Silverman et al., 2008). Unfortunately, these compounds are not highly selective for Panx1 as they also block other channels, including connexins. Side effects of these drugs include pain, severe muscle weakness, mood changes, seizures, psychiatric adverse reactions, and hypertension, which limits their pharmacological potential. As an alternative, many laboratories successfully utilized panx $^{10}$ anti-peptide to block Panx1 function in experimental settings, however, specificity of this reagent has also been disputed (Dahl, 2007). Development of new Panx1 inhibitors with improved pharmacological characteristics and selectivity will undoubtedly benefit investigators and physicians looking to curb Panxl-mediated neurotoxicity in human pathologies.

\section{CONCLUSIONS}

The unique properties of Panx1 channels contribute to the profound neurotoxicity associated with this channel activation during retinal and brain ischemia. The combination of high permeability to ATP, ions, and other molecules, and activation by diverse injury-induced DAMPs, makes Panx1-expressing neurons highly sensitive to mechanical and ischemia injuries. Furthermore, Panx1 works synergistically with other neurotoxic pathways, such as the TLR/TNF receptors-NF- $\kappa \mathrm{B}$ axis facilitating pro-inflammatory cytokine and HMGB1 in many cell types. The involvement of Panx1 in multiple neurotoxic pathways, as well as its proven "druggability" make it a promising target for therapies of progressive neurodegenerations of the retina or brain.

\section{ACKNOWLEDGMENTS}

We thank Dr. A. Hackam for critically reading the manuscript. Supported by NIH NEI grants R01-EY14232, EY021517, Russian Federal Special Program Grant 2012-1.5-12-000-1002018 (Valery I. Shestopalov), EY018666 and GM060019 (Vladlen Z. Slepak), Center Grant P30-EY014801, unrestricted DOD and RPB grants to Bascom Palmer Eye Institute.

\section{REFERENCES}

Abulafia, D. P., de Rivero Vaccari, J. P., Lozano, J. D., Lotocki, G., Keane, R. W., and Dietrich, W. D. (2009). Inhibition of the inflammasome complex reduces the inflammatory response after thromboembolic stroke in mice. J. Cereb. Blood Flow Metab. 29, 534-544. doi: 10.1038/jcbfm. 2008.143

Arai, J., Katai, N., Kuida, K., Kikuchi, T., and Yoshimura, N. (2006). Decreased retinal neuronal cell death in caspase-1 knockout mice. Jpn. J. Ophthalmol. 50, 417-425. doi: 10.1007/s10384-006-0352-y

Ayna, G., Krysko, D. V., Kaczmarek, A., Petrovski, G., Vandenabeele, P., and Fesus, L. (2012). ATP release from dying autophagic cells and their phagocytosis are crucial for inflammasome activation in macrophages. PLOS ONE 7:e40069. doi: 10.1371/journal.pone.0040069

Bales, K. R., Du, Y., Dodel, R. C., Yan, G. M., Hamilton-Byrd, E., and Paul, S. M. (1998). The NF-kappaB/Rel family of proteins mediates Abeta-induced neurotoxicity and glial activation. Brain Res. Mol. Brain Res. 57, 63-72. doi: 10.1016/S0169-328X(98)00066-7

Bao, B. A., Lai, C. P., Naus, C. C., and Morgan, J. R. (2012). Pannexin1 drives multicellular aggregate compaction via a signaling cascade that remodels the actin cytoskeleton. J. Biol. Chem. 287, 8407-8416. doi: 10.1074/jbc.M111.306522

Bao, L., Locovei, S., and Dahl, G. (2004). Pannexin membrane channels are mechanosensitive conduits for ATP. FEBS Lett. 572, 65-68. doi: 10.1016/j.febslet.2004.07.009

Barakat, D. J., Dvoriantchikova, G., Ivanov, D., and Shestopalov, V. I. (2012). Astroglial NF-kappaB mediates oxidative stress by regulation of NADPH oxidase in a model of retinal ischemia reperfusion injury. J. Neurochem. 120, 586-597. doi: 10.1111/j.1471-4159.2011.07595.x

Barbe, M. T., Monyer, H., and Bruzzone, R. (2006). Cell-cell communication beyond connexins: the pannexin channels. Physiology (Bethesda) 21, 103-114. doi: 10.1152/physiol.00048.2005

Bargiotas, P., Krenz, A., Hormuzdi, S. G., Ridder, D. A., Herb, A., Barakat, W., et al. (2011). Pannexins in ischemia-induced neurodegeneration. Proc. Natl. Acad. Sci. U.S.A. 108, 20772-20777. doi: 10.1073/pnas.1018262108

Bennett, M. V., and Goodenough, D. A. (1978). Gap junctions, electrotonic coupling, and intercellular communication. Neurosci. Res. Program Bull. 16, $1-486$.

Bennett, M. V., and Zukin, R. S. (2004). Electrical coupling and neuronal synchronization in the Mammalian brain. Neuron 41, 495-511. doi: 10.1016/S08966273(04)00043-1

Bernier, L. P. (2012). Purinergic regulation of inflammasome activation after central nervous system injury. J. Gen. Physiol. 140, 571-575. doi: 10.1085/jgp.201210875 
Bhalla-Gehi, R., Penuela, S., Churko, J. M., Shao, Q., and Laird, D. W. (2010). Pannexin1 and pannexin3 delivery, cell surface dynamics, and cytoskeletal interactions. J. Biol. Chem. 285, 9147-9160. doi: 10.1074/jbc.M109.082008

Brambilla, R., Dvoriantchikova, G., Barakat, D., Ivanov, D., Bethea, J. R., and Shestopalov, V. I. (2012). Transgenic inhibition of astroglial NF-kappaB protects from optic nerve damage and retinal ganglion cell loss in experimental optic neuritis. J. Neuroinflammation 9:213. doi: 10.1186/1742-2094-9-213

Brambilla, R., Persaud, T., Hu, X., Karmally, S., Shestopalov, V. I., Dvoriantchikova, G., et al. (2009). Transgenic inhibition of astroglial NF-kappa B improves functional outcome in experimental autoimmune encephalomyelitis by suppressing chronic central nervous system inflammation. J. Immunol. 182, 2628-2640. doi: 10.4049/jimmunol.0802954

Brough, D., Pelegrin, P., and Rothwell, N. J. (2009). Pannexin-1-dependent caspase1 activation and secretion of IL-1beta is regulated by zinc. Eur. J. Immunol. 39, 352-358. doi: 10.1002/eji.200838843

Bruzzone, R., Hormuzdi, S. G., Barbe, M. T., Herb, A., and Monyer, H. (2003). Pannexins, a family of gap junction proteins expressed in brain. Proc. Natl. Acad. Sci. U.S.A. 100, 13644-13649. doi: 10.1073/pnas.2233464100

Bunse, S., Locovei, S., Schmidt, M., Qiu, F., Zoidl, G., Dahl, G., et al. (2009). The potassium channel subunit Kvbeta3 interacts with pannexin 1 and attenuates its sensitivity to changes in redox potentials. FEBS J. 276, 6258-6270. doi: 10.1111/j.1742-4658.2009.07334.x

Chekeni, F. B., Elliott, M. R., Sandilos, J. K., Walk, S. F., Kinchen, J. M., Lazarowski, E. R., et al. (2010). Pannexin 1 channels mediate 'find-me' signal release and membrane permeability during apoptosis. Nature 467, 863-867. doi: 10.1038 /nature09413

Choi, B. Y., Jang, B. G., Kim, J. H., Lee, B. E., Sohn, M., Song, H. K., et al. (2012) Prevention of traumatic brain injury-induced neuronal death by inhibition of NADPH oxidase activation. Brain Res. 1481, 49-58. doi: 10.1016/j.brainres.2012.08.032

Dahl, G. (2007). Gap junction-mimetic peptides do work, but in unexpected ways. Cell Commun. Adhes. 14, 259-264. doi: 10.1080/15419060801891018

Dahl, G., and Keane, R. W. (2012). Pannexin: from discovery to bedside in 11+/-4 years? Brain Res. 1487, 150-159. doi: 10.1016/j.brainres.2012.04.058

Dahl, G., Qiu, F., and Wang, J. (2013). The bizarre pharmacology of the ATP release channel pannexin1. Neuropharmacology 75, 583-593. doi: 10.1016/j. neuropharm.2013.02.019

de Rivero Vaccari, J. P., Bastien, D., Yurcisin, G., Pineau, I., Dietrich, W. D., De Koninck, Y., et al. (2012). P2X4 receptors influence inflammasome activation after spinal cord injury. J. Neurosci. 32, 3058-3066. doi: 10.1523/JNEUROSCI.4930-11.2012

de Rivero Vaccari, J. P., Lotocki, G., Alonso, O. F., Bramlett, H. M., Dietrich, W. D., and Keane, R. W. (2009). Therapeutic neutralization of the NLRP1 inflammasome reduces the innate immune response and improves histopathology after traumatic brain injury. J. Cereb. Blood Flow Metab. 29, 1251-1261. doi: 10.1038/jcbfm.2009.46

de Rivero Vaccari, J. P., Lotocki, G., Marcillo, A. E., Dietrich, W. D., and Keane, R. W. (2008) A molecular platform in neurons regulates inflammation after spinal cord injury. J. Neurosci. 28, 3404-3414. doi: 10.1523/JNEUROSCI.0157-08.2008

Doll, R., Hill, I. D., and Hutton, C. F. (1965). Treatment of gastric ulcer with carbenoxolone sodium and oestrogens. Gut 6, 19-24. doi: 10.1136/gut.6.1.19

Domercq, M., Perez-Samartin, A., Aparicio, D., Alberdi, E., Pampliega, O., and Matute, C. (2010). P2X7 receptors mediate ischemic damage to oligodendrocytes. Glia 58, 730-740. doi: 10.1002/glia.20958

Draguhn, A., Traub, R. D., Schmitz, D., and Jefferys, J. G. (1998). Electrical coupling underlies high-frequency oscillations in the hippocampus in vitro. Nature 394, 189-192. doi: 10.1038/28184

Dvoriantchikova, G., Barakat, D., Brambilla, R., Agudelo, C., Hernandez, E., Bethea, J. R., et al. (2009). Inactivation of astroglial NF-kappa B promotes survival of retinal neurons following ischemic injury. Eur. J. Neurosci. 30, 175-185. doi: 10.1111/j.1460-9568.2009.06814.X

Dvoriantchikova, G., Grant, J., Santos, A. R., Hernandez, E., and Ivanov, D. (2012a). Neuronal NAD (P)H oxidases contribute to ROS production and mediate RGC death after ischemia. Invest. Ophthalmol. Vis. Sci. 53, 2823-2830. doi: 10.1167/iovs.12-9526

Dvoriantchikova, G., Ivanov, D., Barakat, D., Grinberg, A., Wen, R., Slepak, V. Z., et al. (2012b). Genetic ablation of Pannexin1 protects retinal neurons from ischemic injury. PLoS ONE 7:e31991. doi: 10.1371/journal.pone.00 31991
Dvoriantchikova, G., Ivanov, D., Panchin, Y., and Shestopalov, V. I. (2006). Expression of pannexin family of proteins in the retina. FEBS Lett. 580, 2178-2182. doi: 10.1016/j.febslet.2006.03.026

Fleshner, M. (2013). Stress-evoked sterile inflammation, danger associated molecular patterns (DAMPs), microbial associated molecular patterns (MAMPs) and the inflammasome. Brain Behav. Immun. 27, 1-7. doi: 10.1016/j.bbi.2012.08.012

Franchi, L., Munoz-Planillo, R., and Nunez, G. (2012). Sensing and reacting to microbes through the inflammasomes. Nat. Immunol. 13, 325-332. doi: 10.1038/ni.2231

Franke, H., Krugel, U., and Illes, P. (2006). P2 receptors and neuronal injury. Pflugers Arch. 452, 622-644. doi: 10.1007/s00424-006-0071-8

Garre, J. M., Retamal, M. A., Cassina, P., Barbeito, L., Bukauskas, F. F., Saez, J. C., et al. (2010). FGF-1 induces ATP release from spinal astrocytes in culture and opens pannexin and connexin hemichannels. Proc. Natl. Acad. Sci. U.S.A. 107, 22659-22664. doi: 10.1073/pnas.1013793107

Godecke, S., Roderigo, C., Rose, C. R., Rauch, B. H., Godecke, A., and Schrader, J. (2012). Thrombin-induced ATP release from human umbilical vein endothelial cells. Am. J. Physiol. Cell Physiol. 302, C915-C923. doi: 10.1152/ajpcell.00283.2010

Goodenough, D. A., Dick, J. S. 2nd., and Lyons, J. E. (1980). Lens metabolic cooperation: a study of mouse lens transport and permeability visualized with freeze-substitution autoradiography and electron microscopy. J. Cell Biol. 86, 576-589. doi: 10.1083/jcb.86.2.576

Gourine, A. V., Dale, N., Llaudet, E., Poputnikov, D. M., Spyer, K. M., and Gourine, V. N. (2007). Release of ATP in the central nervous system during systemic inflammation: real-time measurement in the hypothalamus of conscious rabbits. J. Physiol. 585, 305-316. doi: 10.1113/jphysiol.2007.143933

Gulbransen, B. D., Bashashati, M., Hirota, S. A., Gui, X., Roberts, J. A., MacDonald, J. A., et al. (2012). Activation of neuronal P2X7 receptor-pannexin-1 mediates death of enteric neurons during colitis. Nat. Med. 18, 600-604. doi: $10.1038 / \mathrm{nm} .2679$

Hardingham, G. E. (2009). Coupling of the NMDA receptor to neuroprotective and neurodestructive events. Biochem. Soc. Trans. 37, 1147-11460. doi 10.1042/BST0371147

Iglesias, R., Dahl, G., Qiu, F., Spray, D. C., and Scemes, E. (2009). Pannexin 1: the molecular substrate of astrocyte "hemichannels". J. Neurosci. 29, 7092-7097. doi: 10.1523/JNEUROSCI.6062-08.2009

Iglesias, R., Locovei, S., Roque, A., Alberto, A. P., Dahl, G., Spray, D. C., et al. (2008). P2X7 receptor-Pannexinl complex: pharmacology and signaling. Am. J. Physiol. Cell Physiol. 295, C752-C760. doi: 10.1152/ajpcell.00228.2008

Iglesias, R. M., and Spray, D. C. (2012). Pannexin1-mediated ATP release provides signal transmission between Neuro2A cells. Neurochem. Res. 37, 1355-1363. doi: 10.1007/s11064-012-0720-6

Innocenti, B., Pfeiffer, S., Zrenner, E., Kohler, K., and Guenther, E. (2004). ATPinduced non-neuronal cell permeabilization in the rat inner retina. J. Neurosci. 24, 8577-8583. doi: 10.1523/JNEUROSCI.2812-04.2004

Johnson, A. D., and Owens, G. K. (1999). Differential activation of the SMalpha A promoter in smooth vs. skeletal muscle cells by bHLH factors. Am. J. Physiol. Cell Physiol. 276, C1420-C1431.

Jones, F. S., Kioussi, C., Copertino, D. W., Kallunki, P., Holst, B. D., and Edelman, G. M. (1997). Barx2, a new homeobox gene of the Bar class, is expressed in neural and craniofacial structures during development. Proc. Natl. Acad. Sci. U.S.A. 94, 2632-2637. doi: 10.1073/pnas.94.6.2632

Kanneganti, T. D., Lamkanfi, M., Kim, Y. G., Chen, G., Park, J. H., Franchi, L., et al. (2007). Pannexin-1-mediated recognition of bacterial molecules activates the cryopyrin inflammasome independent of toll-like receptor signaling. Immunity 26, 433-443. doi: 10.1016/j.immuni.2007.03.008

Karatas, H., Erdener, S. E., Gursoy-Ozdemir, Y., Lule, S., Eren-Kocak, E., Sen, Z. D., et al. (2013). Spreading depression triggers headache by activating neuronal panx1 channels. Science 339, 1092-1095. doi: 10.1126/science. 1231897

Kawamura, M. Jr., Ruskin, D. N., and Masino, S. A. (2010). Metabolic autocrine regulation of neurons involves cooperation among pannexin hemichannels, adenosine receptors, and KATP channels. J. Neurosci. 30, 3886-3895. doi: 10.1523/JNEUROSCI.0055-10.2010

Kim, C. H., Neiswender, H., Baik, E. J., Xiong, W. C., and Mei, L. (2008). Beta-catenin interacts with $\mathrm{MyoD}$ and regulates its transcription activity. Mol. Cell. Biol. 28, 2941-2951. doi: 10.1128/MCB 01682-07 
Krizaj, D., Ryskamp, D. A., Tian, N., Tezel, G., Mitchell, C. H., Slepak, V. Z., et al. (2013). From mechanosensitivity to inflammatory responses: new players in the pathology of glaucoma. Curr. Eye Res. 39, 105-119. doi: 10.3109/02713683.2013. 836541

Kumar, A., Velloso, C. P., Imokawa, Y., and Brockes, J. P. (2004). The regenerative plasticity of isolated urodele myofibers and its dependence on MSX1. PLoS Biol. 2:E218. doi: 10.1371/journal.pbio.0020218

Lamkanfi, M. (2011). Emerging inflammasome effector mechanisms. Nat. Rev. Immunol. 11, 213-20. doi: 10.1038/nri2936

Lamkanfi, M., Sarkar, A., Vande Walle, L., Vitari, A. C., Amer, A. O., Wewers, M. D., et al. (2010). Inflammasome-dependent release of the alarmin HMGB1 in endotoxemia. J. Immunol. 185, 4385-4392. doi: 10.4049/jimmunol.1000803

Lazarewicz, J. W., Wroblewski, J. T., and Costa, E. (1990). N-methyl-D-aspartatesensitive glutamate receptors induce calcium-mediated arachidonic acid release in primary cultures of cerebellar granule cells. J. Neurochem. 55, 1875-1881. doi: 10.1111/j.1471-4159.1990.tb05771.x

Li, A., Leung, C. T., Peterson-Yantorno, K., Stamer, W. D., Mitchell, C. H., and Civan, M. M. (2012). Mechanisms of ATP release by human trabecular meshwork cells, the enabling step in purinergic regulation of aqueous humor outflow. J. Cell. Physiol. 227, 172-182. doi: 10.1002/jcp.22715

Li, S., Tomic, M., and Stojilkovic, S. S. (2011). Characterization of novel Pannexin 1 isoforms from rat pituitary cells and their association with ATP-gated P2X channels. Gen. Comp. Endocrinol. 174, 202-210. doi: 10.1016/j.ygcen.2011.08.019

Li, W., Li, J., Sama, A. E., and Wang, H. (2013). Carbenoxolone blocks endotoxininduced PKR activation and HMGB1 release. Mol Med. 19, 203-211. doi: 10.2119/molmed.2013.00064

Lobner, D., and Lipton, P. (1993). Intracellular calcium levels and calcium fluxes in the CAl region of the rat hippocampal slice during in vitro ischemia: relationship to electrophysiological cell damage. J. Neurosci. 13, 4861-4871.

Locovei, S., Bao, L., and Dahl, G. (2006a). Pannexin 1 in erythrocytes: function without a gap. Proc. Natl. Acad. Sci. U.S.A. 103, 7655-7659. doi: 10.1073/pnas.0601037103

Locovei, S., Wang, J., and Dahl, G. (2006b). Activation of pannexin 1 channels by ATP through P2Y receptors and by cytoplasmic calcium. FEBS Lett. 580, 239-244. doi: 10.1016/j.febslet.2005.12.004

Locovei, S., Scemes, E., Qiu, F., Spray, D. C., and Dahl, G. (2007). Pannexin1 is part of the pore forming unit of the $\mathrm{P} 2 \mathrm{X}(7)$ receptor death complex. FEBS Lett. 581, 483-488. doi: 10.1016/j.febslet.2006.12.056

Maher, J. J. (2009). DAMPs ramp up drug toxicity. J. Clin. Invest. 119, 246-249. doi: $10.1172 / \mathrm{JCI} 38178$

Matute, C., and Cavaliere, F. (2011). Neuroglial interactions mediated by purinergic signalling in the pathophysiology of CNS disorders. Semin. Cell Dev. Biol. 22, 252-259. doi: 10.1016/j.semcdb.2011.02.011

Meloni, B. P., Meade, A. J., Kitikomolsuk, D., and Knuckey, N. W. (2011). Characterisation of neuronal cell death in acute and delayed in vitro ischemia (oxygen-glucose deprivation) models. J. Neurosci. Methods 195, 67-74. doi: 10.1016/j.jneumeth.2010.11.023

Melov, S., Tarnopolsky, M. A., Beckman, K., Felkey, K., and Hubbard, A. (2007). Resistance exercise reverses aging in human skeletal muscle. PLOS ONE 2:e465. doi: 10.1371/journal.pone.0000465

Mochizuki, T., Sokabe, T., Araki, I., Fujishita, K., Shibasaki, K., Uchida, K., et al. (2009). The TRPV4 cation channel mediates stretch-evoked Ca2+ influx and ATP release in primary urothelial cell cultures. J. Biol. Chem. 284, 21257-21264. doi: 10.1074/jbc.M109.020206

Nowak, K. J., and Davies, K. E. (2004). Duchenne muscular dystrophy and dystrophin: pathogenesis and opportunities for treatment. EMBO Rep. 5, 872-876. doi: 10.1038/sj.embor.7400221

Orellana, J. A., Froger, N., Ezan, P., Jiang, J. X., Bennett, M. V., Naus, C. C., et al. (2011). ATP and glutamate released via astroglial connexin 43 hemichannels mediate neuronal death through activation of pannexin 1 hemichannels. J. Neurochem. 118, 826-840. doi: 10.1111/j.1471-4159.2011.07210.x

Orellana, J. A., Hernandez, D. E., Ezan, P., Velarde, V., Bennett, M. V., Giaume, C., et al. (2010). Hypoxia in high glucose followed by reoxygenation in normal glucose reduces the viability of cortical astrocytes through increased permeability of connexin 43 hemichannels. Glia 58, 329-343. doi: 10.1002/glia.20926

Orellana, J. A., Saez, P. J., Shoji, K. F., Schalper, K. A., Palacios-Prado, N., Velarde, V., et al. (2009). Modulation of brain hemichannels and gap junction channels by pro-inflammatory agents and their possible role in neurodegeneration. Antioxid. Redox Signal. 11, 369-399. doi: 10.1089/ars.2008.2130
Paramo, B., Montiel, T., Hernandez-Espinosa, D. R., Rivera-Martinez, M., Moran, J., and Massieu, L. (2013). Calpain activation induced by glucose deprivation is mediated by oxidative stress and contributes to neuronal damage. Int. J. Biochem. Cell Biol. 45, 2596-2604. doi: 10.1016/j.biocel.2013.08.013

Pelegrin, P. (2008). Targeting interleukin-1 signaling in chronic inflammation: focus on P2X(7) receptor and Pannexin-1. Drug News Perspect. 21, 424-433. doi: 10.1358/dnp.2008.21.8.1265800

Pelegrin, P., Barroso-Gutierrez, C., and Surprenant, A. (2008). P2X7 receptor differentially couples to distinct release pathways for IL-1beta in mouse macrophage. J. Immunol. 180, 7147-7157.

Pelegrin, P., and Surprenant, A. (2006). Pannexin-1 mediates large pore formation and interleukin-1beta release by the ATP-gated P2X7 receptor. EMBO J. 25, 5071-5082. doi: 10.1038/sj.emboj.7601378

Pelegrin, P., and Surprenant, A. (2007). Pannexin-1 couples to maitotoxin- and nigericin-induced interleukin-1beta release through a dye uptake-independent pathway. J. Biol. Chem. 282, 2386-2394. doi: 10.1074/jbc.M610351200

Pelegrin, P., and Surprenant, A. (2009). The P2X(7) receptor-pannexin connection to dye uptake and IL-1beta release. Purinergic Signal. 5, 129-137. doi: 10.1007/s11302-009-9141-7

Prochnow, N., Abdulazim, A., Kurtenbach, S., Wildforster, V., Dvoriantchikova, G., Hanske, J., et al. (2012). Pannexin1 stabilizes synaptic plasticity and is needed for learning. PLoS ONE 7:e51767. doi: 10.1371/journal.pone.0051767

Qu, Y., Misaghi, S., Newton, K., Gilmour, L. L., Louie, S., Cupp, J. E., et al. (2011). Pannexin-1 is required for ATP release during apoptosis but not for inflammasome activation. J. Immunol. 186, 6553-6561. doi: 10.4049/jimmunol.1100478

Reigada, D., Lu, W., Zhang, M., and Mitchell, C. H. (2008). Elevated pressure triggers a physiological release of ATP from the retina: possible role for pannexin hemichannels. Neuroscience 157, 396-404. doi: 10.1016/j.neuroscience.2008.08.036

Reuss, B., Hertel, M., Werner, S., and Unsicker, K. (2000). Fibroblast growth factors-5 and -9 distinctly regulate expression and function of the gap junction protein connexin 43 in cultured astroglial cells from different brain regions. Glia 30, 231-241. doi: 10.1002/(SICI) 1098-1136(200005)30:3<231::AIDGLIA3 > 3.0.CO;2-1

Riteau, N., Baron, L., Villeret, B., Guillou, N., Savigny, F., Ryffel, B., et al. (2012). ATP release and purinergic signaling: a common pathway for particle-mediated inflammasome activation. Cell Death Dis. 3:e403. doi: 10.1038/cddis.2012.144

Rosenbaum, D. M., Degterev, A., David, J., Rosenbaum, P. S., Roth, S., Grotta, J. C., et al. (2010). Necroptosis, a novel form of caspase-independent cell death, contributes to neuronal damage in a retinal ischemia-reperfusion injury model. J. Neurosci. Res. 88, 1569-1576. doi: 10.1002/jnr.22314

Ryskamp, D. A., Witkovsky, P., Barabas, P., Huang, W., Koehler, C., Akimov, N. P., et al. (2011). The polymodal ion channel transient receptor potential vanilloid 4 modulates calcium flux, spiking rate, and apoptosis of mouse retinal ganglion cells. J. Neurosci. 31, 7089-7101. doi: 10.1523/JNEUROSCI.0359-11.2011

Saez, J. C., Schalper, K. A., Retamal, M. A., Orellana, J. A., Shoji, K. F., and Bennett, M. V. (2010). Cell membrane permeabilization via connexin hemichannels in living and dying cells. Exp. Cell Res. 316, 2377-2389. doi: 10.1016/j.yexcr.2010. 05.026

Sandilos, J. K., Chiu, Y. H., Chekeni, F. B., Armstrong, A. J., Walk, S. F., Ravichandran, K. S., et al. (2012). Pannexin 1, an ATP release channel, is activated by caspase cleavage of its pore-associated C-terminal autoinhibitory region. J. Biol. Chem. 287, 11303-11311. doi: 10.1074/jbc.M111.323378

Seil, M., Fontanils, U., Etxebarria, I. G., Pochet, S., Garcia-Marcos, M., Marino, A., et al. (2008). Pharmacological evidence for the stimulation of NADPH oxidase by $\mathrm{P} 2 \mathrm{X}(7)$ receptors in mouse submandibular glands. Purinergic Signal. 4, 347-355. doi: 10.1007/s11302-008-9118-y

Seminario-Vidal, L., Okada, S. F., Sesma, J. I., Kreda, S. M., van Heusden, C. A., Zhu, Y., et al. (2011). Rho signaling regulates pannexin 1-mediated ATP release from airway epithelia. J. Biol. Chem. 286, 26277-26286. doi: 10.1074/jbc.M111.260562

Shahidullah, M., Mandal, A., and Delamere, N. A. (2012). TRPV4 in porcine lens epithelium regulates hemichannel-mediated ATP release and Na-K-ATPase activity. Am. J. Physiol. Cell Physiol. 302, C1751-C1761. doi: 10.1152/ajpcell.00010.2012

Shiose, S., Chen, Y., Okano, K., Roy, S., Kohno, H., Tang, J., et al. (2011). Toll-like receptor 3 is required for development of retinopathy caused by impaired all-trans-retinal clearance in mice. J. Biol. Chem. 286, 15543-15555. doi: 10.1074/jbc.M111.228551 
Silverman, W., Locovei, S., and Dahl, G. (2008). Probenecid, a gout remedy, inhibits pannexin 1 channels. Am. J. Physiol. Cell Physiol. 295, C761-C767. doi: 10.1152/ajpcell.00227.2008

Silverman, W. R., de Rivero Vaccari, J. P., Locovei, S., Qiu, F., Carlsson, S. K., Scemes, E., et al. (2009). The pannexin 1 channel activates the inflammasome in neurons and astrocytes. J. Biol. Chem. 284, 18143-18151. doi: 10.1074/jbc.M109.004804

Striedinger, K., Petrasch-Parwez, E., Zoidl, G., Napirei, M., Meier, C., Eysel, U. T., et al. (2005). Loss of connexin36 increases retinal cell vulnerability to secondary cell loss. Eur. J. Neurosci. 22, 605-616. doi: 10.1111/j.1460-9568.2005.04228.x

Strowig, T., Henao-Mejia, J., Elinav, E., and Flavell, R. (2012). Inflammasomes in health and disease. Nature 481, 278-286. doi: 10.1038/nature10759

Suadicani, S. O., Iglesias, R., Wang, J., Dahl, G., Spray, D. C., and Scemes, E. (2012). ATP signaling is deficient in cultured Pannexin1-null mouse astrocytes. Glia 60, 1106-1116. doi: 10.1002/glia.22338

Sucher, N. J., Lipton, S. A., and Dreyer, E. B. (1997). Molecular basis of glutamate toxicity in retinal ganglion cells. Vision Res. 37, 3483-3493. doi: 10.1016/S00426989(97)00047-3

Thompson, R. J., Jackson, M. F., Olah, M. E., Rungta, R. L., Hines, D. J., Beazely, M. A., et al. (2008). Activation of pannexin-1 hemichannels augments aberrant bursting in the hippocampus. Science 322, 1555-1559. doi: 10.1126/science.1165209

Thompson, R. J., Zhou, N., and MacVicar, B. A. (2006). Ischemia opens neuronal gap junction hemichannels. Science 312, 924-927. doi: 10.1126/science.1126241

Trenholme, C. M., Williams, R. L., Desjardins, R. E., Frischer, H., Carson, P. E., Rieckmann, K. H., et al. (1975). Mefloquine (WR 142,490) in the treatment of human malaria. Science 190, 792-794. doi: 10.1126/science. 1105787

Vanden Abeele, F., Bidaux, G., Gordienko, D., Beck, B., Panchin, Y. V., Baranova, A. V., et al. (2006). Functional implications of calcium permeability of the channel formed by pannexin 1. J. Cell Biol. 174, 535-546. doi: 10.1083/jcb.200601115

Weilinger, N. L., Maslieieva, V., Bialecki, J., Sridharan, S. S., Tang, P. L., and Thompson, R. J. (2013). Ionotropic receptors and ion channels in ischemic neuronal death and dysfunction. Acta Pharmacol. Sin. 34, 39-48. doi: 10.1038/aps.2012.95

Weilinger, N. L., Tang, P. L., and Thompson, R. J. (2012). Anoxia-induced NMDA receptor activation opens pannexin channels via Src family kinases. J. Neurosci. 32, 12579-12588. doi: 10.1523/JNEUROSCI.1267-12.2012

Wicki-Stordeur, L. E., Dzugalo, A. D., Swansburg, R. M., Suits, J. M., and Swayne, L. A. (2012). Pannexin 1 regulates postnatal neural stem and progenitor cell proliferation. Neural Dev. 7:11. doi: 10.1186/1749-8104-7-11

Willingham, S. B., Allen, I. C., Bergstralh, D. T., Brickey, W. J., Huang, M. T., Taxman, D. J., et al. (2009). NLRP3 (NALP3, Cryopyrin) facilitates in vivo caspase- 1 activation, necrosis, and HMGB1 release via inflammasomedependent and -independent pathways. J. Immunol. 183, 2008-2015. doi: 10.4049/jimmunol.0900138

Wurm, A., Lipp, S., Pannicke, T., Linnertz, R., Krugel, U., Schulz, A., et al. (2010). Endogenous purinergic signaling is required for osmotic volume regulation of retinal glial cells. J. Neurochem. 112, 1261-1272. doi: 10.1111/j.1471-4159.2009. 06541.x

Wurm, A., Pannicke, T., Wiedemann, P., Reichenbach, A., and Bringmann, A. (2008). Glial cell-derived glutamate mediates autocrine cell volume regulation in the retina: activation by VEGF. J. Neurochem. 104, 386-399. doi: 10.1111/j.1471-4159.2007.04992.x

Xia, J., Lim, J. C., Lu, W., Beckel, J. M., Macarak, E. J., Laties, A. M., et al. (2012). Neurons respond directly to mechanical deformation with pannexin-mediated ATP release and autostimulation of P2X7 receptors. J. Physiol. 590(Pt 10), 2285-2304. doi: 10.1113/jphysiol.2012.227983

Yang, H., Hreggvidsdottir, H. S., Palmblad, K., Wang, H., Ochani, M., Li, J., et al. (2010). A critical cysteine is required for HMGB1 binding to Toll-like receptor 4 and activation of macrophage cytokine release. Proc. Natl. Acad. Sci. U.S.A. 107, 11942-11947. doi: 10.1073/pnas.1003893107

Zhang, L., Deng, T., Sun, Y., Liu, K., Yang, Y., and Zheng, X. (2008). Role for nitric oxide in permeability of hippocampal neuronal hemichannels during oxygen glucose deprivation. J. Neurosci. Res. 86, 2281-2291. doi: 10.1002/jnr.21675

Zhang, M., Piskuric, N. A., Vollmer, C., and Nurse, C. A. (2012). P2Y2 receptor activation opens pannexin-1 channels in rat carotid body type II cells: potential role in amplifying the neurotransmitter ATP. J. Physiol. 590(Pt 17), 4335-4350. doi: 10.1113/jphysiol.2012.236265

Zhang, X., Zhang, M., Laties, A. M., and Mitchell, C. H. (2005a). Stimulation of $\mathrm{P} 2 \mathrm{X} 7$ receptors elevates $\mathrm{Ca} 2+$ and kills retinal ganglion cells. Invest. Ophthalmol. Vis. Sci. 46, 2183-2191. doi: 10.1167/iovs.05-0052

Zhang, Z., Trautmann, K., and Schluesener, H. J. (2005b). Microglia activation in rat spinal cord by systemic injection of TLR3 and TLR7/8 agonists. J. Neuroimmunol. 164, 154-160. doi: 10.1016/j.jneuroim.2005.03.014

Zoidl, G., Petrasch-Parwez, E., Ray, A., Meier, C., Bunse, S., Habbes, H. W., et al. (2007). Localization of the pannexinl protein at postsynaptic sites in the cerebral cortex and hippocampus. Neuroscience 146, 9-16. doi: 10.1016/j.neuroscience.2007.01.061

Conflict of Interest Statement: The authors declare that the research was conducted in the absence of any commercial or financial relationships that could be construed as a potential conflict of interest.

Received: 11 November 2013; accepted: 10 January 2014; published online: 11 February 2014.

Citation: Shestopalov VI and Slepak VZ (2014) Molecular pathways of pannexin1mediated neurotoxicity. Front. Physiol. 5:23. doi: 10.3389/fphys.2014.00023

This article was submitted to Membrane Physiology and Membrane Biophysics, a section of the journal Frontiers in Physiology.

Copyright (c) 2014 Shestopalov and Slepak. This is an open-access article distributed under the terms of the Creative Commons Attribution License (CC BY). The use, distribution or reproduction in other forums is permitted, provided the original author(s) or licensor are credited and that the original publication in this journal is cited, in accordance with accepted academic practice. No use, distribution or reproduction is permitted which does not comply with these terms. 